\title{
Investigação entre o mundo real e a representação virtual em situações encontradas no jogo Tomb Raider
} Investigative study between the real world and virtual representation in situations found in the game Tomb Raider

\author{
André Schlemmer \& Diego Normandi
}

game design, semântica e semiótica, representação real e virtual

\begin{abstract}
Ao observar os jogos de videogame atuais, as representações gráficas estão próximas do mundo real. Os designers de jogos tentam transpor o real para o virtual, e com isso, buscam maior profundidade interativa fluídica para o jogador. A proposta deste artigo é realizar estudo investigativo entre o mundo real e a representação virtual em um jogo de videogame. A proposta é fundamentada em conceitos semânticos e semióticos perante os sistemas de informações em games. O estudo investigativo foi realizado por técnica de observação espontânea através de três situações encontradas no jogo. Para cada situação foi aplicado questionamentos elaborados pela literatura consultada, e em seguida, foi realizado uma análise comparativa pelos pesquisadores. Como resultado, a qualidade da representação visual é verossímil ao realismo, mas ainda existe a lacuna perante o que o jogador visualmente vê e o comportamento dos objetos durante a atuação no jogo. Por isso, a relação de estímulos cognitivos fornecidas para o jogador pode comprometer a interpretação correta destes objetos, afetando a jogabilidade e a capacidade de interpretação dos significados carregados nestes signos. Por outro lado, o desenvolvedor de games precisa sustentar, na projetação, alguns requisitos e restrições que permitem o fluxo da narrativa e a interação com o jogador, sendo fatores que influenciam diretamente na linguagem representada de tais objetos no mundo virtual, ocasionando alterações ou diferenciações do mundo real.
\end{abstract}

game design, semantics and semiotics, real and virtual representation

When looking at current video-game games the graphical representations are close to real world, thereby game designers try to transpose the real to the virtual, and with that, they seek to provide a greater interactive fluidic depth for the player. The purpose of this article is conducting an investigative study between the real world and virtual representation in a game. This proposal is based on semantic and semiotic concepts in relation to information systems in games. The investigative study was conducted by a technique of spontaneous observation through three situations found in the game. For each situation, were applied questions elaborated through the consulted literature, and then a comparative analysis was applied by researchers. As result, the quality of the visual representation is similar to realism, but there is still the gap towards what the player visually sees and the behavior of the objects while playing. Therefore, the relation of cognitive stimuli provided to the player can compromise a correct interpretation of these objects, affecting the gameplay and capacity of interpretation of meanings loaded in these signs, in contrast, the game designer needs to sustain, in the project, some requirements and restrictions that allow the flow of the narrative and the interaction with the player, this way are factors that directly influence the represented language of such objects in the virtual world, causing alterations or differentiations of the real world.

\section{Introdução}

O levantamento feito em junho de 2017 pela NewZoo, registrou 66,3 milhões de jogadores e prospectou receita de US $\$ 1,3$ bilhão, colocando o Brasil na posição de $13^{\circ}$ maior mercado de games do mundo (Newzoo, 2017). Esse segmento apresenta oportunidades rentáveis a serem exploradas, além dos números comprovarem que existem usuários e um consumo em expansão, como também, profissionais que desenvolvem games, projetos que englobam interfaces digitais e programação.

Esse cenário mostra dois agentes importantes do mercado de games, o desenvolvedor e o

Anais do 9 CIDI e 9 CONGIC

Luciane Maria Fadel, Carla Spinillo, Anderson Horta,

Cristina Portugal (orgs.)

Sociedade Brasileira de Design da Informação - SBDI

Belo Horizonte | Brasil | 2019

ISBN $978-85-212-1728-2$
Proceedings of the 9th CIDI and 9th CONGIC

Luciane Maria Fadel, Carla Spinillo, Anderson Horta, Cristina Portugal (orgs.)

Sociedade Brasileira de Design da Informação - SBDI Belo Horizonte | Brazil | 2019

ISBN $978-85-212-1728-2$ 
jogador, sendo assim, tem o profissional que desenvolve o sistema informacional que permite ao jogador consumir tal informação. Essas informações são projetas em uma interface, e durante a interação o jogador vivência suas experiências, portanto, a informação transmite ao jogador um processo comunicativo pelo qual requer uma interpretação.

Partindo desta explanação, o desenvolvedor proporciona ao jogo elementos que fomentam sua narrativa tanto da ambientação, de acordo com suas características (por exemplo, ação primeira pessoa - tiro), quanto as necessidades buscadas pelo jogador. Desse contexto, percebe-se que os jogos de videogame atuais estão sendo construídos a partir de representações gráficas realistas, buscando uma maior profundidade interativa fluídica para o jogador.

Sendo assim, os jogos entregam ao jogador uma interpretação mais significativa do que está sendo vivenciado, provocando alguns questionamentos: os elementos representados no universo virtual entregam as mesmas características do mundo real? As propriedades dos objetos representados em contexto de uso durante o jogo são mesmo realistas em comparação com o mundo real?

A proposta deste artigo é investigar se os objetos em seu contexto de uso nos jogos ocasionam as mesmas situações ao comparar com o mundo real. Essa proposta está fundamentada em conceitos semânticos e semióticos perante os sistemas de informações em games, ou seja, até que ponto o desenvolvedor proporciona um nivelamento do processo de significação entre o real e o virtual para preencher as necessidades dos jogadores.

\section{Design da Informação e a Linguagem Visual}

O design da informação pode ser entendido como "a arte e a ciência da preparação da informação de modo que possa ser usada pelos humanos com eficiência e eficácia" (HORN, 1999, p.15). Para o Instituto Internacional de Design da Informação você precisa definir, planejar e formatar os conteúdos de uma mensagem e os ambientes em que são apresentados para satisfazer as necessidades informacionais dos usuários pretendidos (IIID, 2018).

O que importar neste processo de compor a informação é a clareza da comunicação, mesmo que os usuários esperem apresentações esteticamente agradáveis e/ou intelectualmente recompensadoras, como também, que a comunicação seja interpretada e compreendida corretamente pela maioria dos usuários pretendidos (Pettersson, 2012). Além disso, segundo Redish (2000), na maior parte do tempo os usuários que consomem informações funcionais estão usando essas informações para atingir uma meta pessoal e são eles quem decidem quanto tempo e esforço serão dedicados em encontrar e entender as informações de que precisam.

Para codificar, armazenar e decodificar informações utilizamos a linguagem como recurso de comunicação, nessa linguagem existe um sistema de símbolos que são atribuídos significados, em sua estrutura existe uma lógica com o intuito de facilitar a informação codificada (Dondis, 2007). Segundo Horn (1999) a linguagem visual é atrelada pela junção estreita de palavras, imagens e formas, o autor reforça que se houver a retirada de um desses elementos o significado é comprometido, pois essa junção forma uma unidade de comunicação, então a integralidade desses elementos é importante, e por isso, se faz necessário entender como funcionam juntos.

No sentido da linguagem visual em jogos, existe uma importância na composição de vários elementos, destaque para forma e cor, nessa composição o jogador aprende a linguagem visual e se comunica através de um controle e status do jogo (Lightbown, 2015). A partir do momento em que o jogador aprendeu a linguagem e se comunica com o jogo, isso converge em uma conversação, e quanto mais próximo a representação destes elementos forem similares em outros jogos do mesmo gênero, mais rapidamente o jogador aprenderá a linguagem visual (Lightbown, 2015).

Tendo uma base de definições da linguagem visual, observa-se que não existe uma singularidade. Neste aspecto, Erwig, Smeltzer e Wang (2017, p. 16) realizaram análise com 
abordagem descritiva sobre as definições que envolvem a linguagem visual, identificando tendências. Os autores concluíram que a linguagem visual é "uma linguagem cuja estrutura sintática pode ser classificada como gráfico, divisão em partes ou ícone", e dos aspectos essenciais o que prevalece é a organização sistêmica do espaço.

Por intermédio deste cenário, conclui-se que para o estudo investigativo existe um processo para compor a informação que será codificada em uma linguagem, e como é feita a composição/organização desta linguagem interfere na interpretação e compreensão do jogador. Como corrobora Frascara (2004), que a percepção visual ajuda a compreender esse ato comunicacional que envolve a organização de estímulos em uma ordem significante.

Esses estímulos são aguçados a partir do momento em que depara-se com a visualização da informação, Malamed (2011, p. 09) explica que ao visualizar, "perguntamos imediatamente: O que é isso? e O que significa isso?", esse ato faz com que examinamos "nossos registros da memória, invocar associações e emoções, e usar o que já sabemos interpretar e inferir significado sobre o desconhecido". Por isso, "quanto mais organizados forem os estímulos em relação ao estilo cognitivo do público, mais fácil será interpretá-los. É por isso que é tão importante usar símbolos pertinentes em mensagens gráficas e organizá-las de acordo com sistemas que sejam compreensíveis pelo público" (Frascara, 2004, p. 66).

\section{O Design da Informação e a Linguagem Visual}

No estudo de Kessing, Tutenel e Bidarra (2012) a discussão da forma de representar visualmente informações do mundo real para o virtual tomam corpo. Os autores discutem que os jogos atuais, principalmente, depois da expansão do 2D para 3D forneceram um realismo estremo ao representar ambientes e objetos que devem ser utilizados para interagir e prosseguir na narrativa do jogo. Mas, se os jogos trazem essa representação da realidade, a interpretação do jogador perante o que se apresenta ocasiona um sentimento, um comportamento e reação semelhante ao que se sucede do mundo real.

Se os jogos retratam a realidade, será mais perceptível para o jogador que os objetos se comportem da mesma forma, porém Kessing, Tutenel e Bidarra (2012) indagam que a qualidade da representação destes objetos está avançando extremamente para o realismo, mas maior será a lacuna entre o que o jogador visualmente vê e comportamentalmente atua no jogo.

Kessing, Tutenel e Bidarra (2012) expõem, neste sentido, que para manter as representações de um objeto real no mundo dos jogos, são envolvidas muitas questões técnicas, pois existe uma integração de vários componentes diferentes ao mesmo tempo, por exemplo, cenário e ambientação. Reforçam ainda, que os objetos são representados em um conjunto de propriedades que envolvem facilidades e/ou barreiras durante o desenvolvimento do jogo e sua própria jogabilidade.

No mesmo estudo, Kessing, Tutenel e Bidarra (2012, p. 03) exemplificam alguns elementos que fazem parte da composição que levam os desenvolvedores a criarem a narrativa e as ações do jogo, que posteriormente causará a interpretação do significado pelo jogador. "Aquilo que é percebido ou conhecido como tendo uma existência distinta" recebe características que os autores denominam como entidades semânticas. A Figura 1 ilustra essas características: 


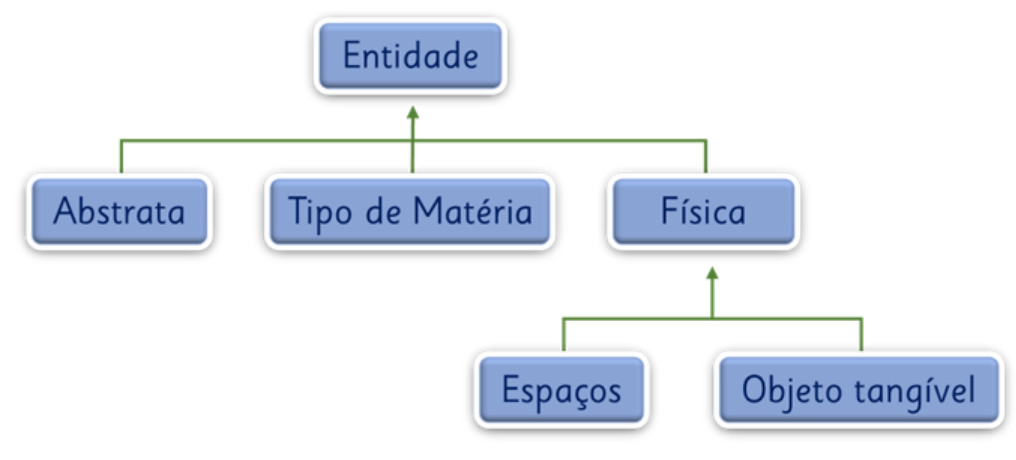

Para produzir a representação de cada entidade existem atributos (por exemplo: comestível, cor, conforto, etc) que expressam valores e formam categorias de unidade. Além disso, as entidades recebem em sua representação um grupo de estados (por exemplo, ligado ou desligado), e essas entidades são divididas em duas classes:

- Abstratas: não possuem uma representação física no mundo, embora estejam presentes de alguma outra forma, por exemplo, inventário de itens coletados durante o jogo ou seleção de qual arma usar).

- Físicas: estão presentes no mundo, têm uma posição particular e geralmente estão sujeitas a atributos físicos.

Das entidades físicas, predomina os objetivos tangíveis, compostos por um tipo de matéria (tudo o que tem massa e ocupa espaço). Para formar essa matéria, se requer um conjunto de condições físicas em um estado particular e representado de certa forma. Para reforçar o entendimento, os autores exemplificam situações, como um casaco que aquece o objeto que ele cobre ou o material de madeira que se representa como inflamável (Kessing, Tutenel, \& Bidarra, 2012).

Outro componente dos objetos tangíveis são os espaços. Nos jogos, representam regiões limitadas com semântica específica, por exemplo um bolso da jaqueta é um espaço possível, assim como pontos de verificação ou áreas que acionam armadilhas (Kessing, Tutenel, \& Bidarra, 2012).

Além de apresentar os conceitos das entidades individuais, os autores identificam conceitos entre entidades. O primeiro deles é "relações", que são formadas por uma entidade de origem e de destino satisfazendo um conjunto de condições ou agrupamento, por exemplo, uma fazenda, que pode conter uma cerca, um campo e uma vaca. O segundo é "serviços", utilizados semanticamente para especificar comportamentos com funções particulares, por exemplo, uma jaqueta tem o serviço de fornecer calor à pessoa que a usa, então o serviço é um gerador de ações dentro de um contexto.

A partir da definição de serviços, pode-se entender que uma ação exercida pela entidade e/ou entidades se faz necessário um contexto. Quando o contexto é acompanhado por um ator, apresenta-se um evento, no qual, obrigatoriamente, o contexto precisa descrever todas as condições para acionar tal evento: o nível de vida chegando a zero - o jogador poderá morrer (atributos) em seguida; um objeto de madeira pode quebrar (matéria); uma chave só abre uma única porta (aquela com a qual ela tem uma relação). Além disso, os eventos são acompanhados por noção de tempo e efeitos: beber uma poção pode curar o alvo gradualmente ao longo do tempo. (Kessing, Tutenel, \& Bidarra, 2012).

Ainda correlacionado com a representação entre o real e o virtual, Novak (2012, p. 214) relata que o desenvolver de jogos trabalha com desenho de níveis, definido como "a criação de ambientes, cenários ou missões em um jogo eletrônico". Nesse sentido, é o responsável pela criação da representação entre o mundo real e o virtual compondo seus desenhos de níveis para os jogos. Segundo Novak (2012), os objetivos de cada nível determinam o desafio e a dificuldade que o jogador terá que passar para progredir no jogo. 


\section{A Semântica e a Semiótica}

De modo geral, a semântica é o "estudo do significado a partir de uma perspectiva linguística" (Hartley, 2004, p.03). Nesse conceito chave, Hartley (2004) explica que a semântica propõe analisar e explicar como os significados são expressos na linguagem, além do mais, a semântica busca compreensão entre as conexões com a realidade extralinguística e a capacidade de se referir para fora da linguagem que geram os significados.

Buscando uma inserção da semântica nos games, Tutenel et al. (2008, p. 57:2) definem como "a informação que transmite o significado de (um objeto em) um mundo virtual". Os autores explicam que ao incluir informações semânticas na representação do objeto temos um comportamento real em um objeto virtual, fazendo com que esses objetos recebam uma incorporação substancial de conhecimento sobre si mesmo e em seu entorno.

No estudo apresentado por Kessing, Tutenel e Bidarra (2012), foi relatado que no mundo dos jogos perde-se a semântica, ou seja, no processo de implantação existe um potencial de ocasionar a falta de consistência em seu conteúdo, o que compromete e afeta nas relações do jogo e a interação com os jogadores. Reforçando essa ideia, Frascara (2004) explica que o conteúdo semântico depende da seleção dos componentes da mensagem que se quer transmitir, e a organização desses componentes vão reforçar o significado, então, se for mal apresentado os componentes podem dificultar o processamento e a compreensão da mensagem pelos jogadores.

No campo semiótico, para Saussure (1971) a linguagem é um sistema de signos expressando ideias. Eco (1979) expõe que a definição de Saussure promoveu uma correlação entre signo-função, intensificando a noção de um signo perante as relações entre significante e significado. Eco (1979, p.14) reforça que, na teoria de Saussure, o significado "é algo que tem a ver com a atividade mental de alguém que recebe um significante", sendo assim, o signo é "implicitamente considerado como um dispositivo comunicativo".

Eco (1979, p.15) propõem, com base na teoria peirciana, que um signo apresenta uma "base em uma convenção social previamente estabelecida, pode ser tomado como algo que representa outra coisa", e esse signo carrega em si algum aspecto ou capacidade de interpretação. Assim, para caracterizar um signo entende-se que requer uma interpretação de um intérprete, que cria a função de tal signo estabelecida por um código, e isso, produz a existência de uma significação. Neste cenário, Peirce (2005, p. 46) confirma que um signo é "aquilo que, sob certo aspecto ou modo, representa algo para alguém. Dirige-se a alguém, isto é, cria, na mente dessa pessoa, um signo equivalente, ou talvez um signo mais desenvolvido".

Se a semiótica estuda como os significados são feitos e fomenta discussões de quais signos representam ou denotam algo/alguma coisa para alguém, esses fatores são considerados por Salen e Zimmerman (2004) uma preocupação central no campo de Game Design.

Para Salen e Zimmerman (2004, p.41) o design é "o processo pelo qual um designer cria um contexto a ser encontrado por um participante, a partir do qual emerge o significado", sendo assim, o designer de jogos cria um contexto de espaços, objetos, narrativas e comportamentos em que os participantes (jogadores) habitam, exploram e manipulam esses contextos.

O processo criado pelo designer de jogos resulta em uma ação entregue ao jogador durante o jogo. Essas ações precisam ser significativas, pois são elas que envolvem e fazem o jogador interpretar e construir as interações durante o jogo. Esse princípio interativo é retirado do mundo real, pois as pessoas interagem com objetos e contextos e criam situações que demandam entendimento entre interpretação e significado. (Salen \& Zimmerman, 2004).

Partindo do preceito de que os designers de jogos precisam criar conceitos de significados em sistemas de interação, a semiótica é a base para construir o conceito de jogos significativos, desde como os significados são feitos até quais signos representam ou denotam informações durante a criação do jogo são fundamentais no processo do Game Design. 


\section{Método}

O estudo apresentado neste artigo tem como finalidade uma pesquisa básica com propósito exploratório usando a técnica de observação espontânea, apresentando uma maior familiaridade entre a representação real e virtual de situações encontradas em um jogo, expondo os fatos observáveis com o intuito de favorecer uma aproximação do fenômeno pesquisado (Gil, 2017).

Com base em Novak (2012) o estudo foi realizado por intermédio do console PlayStation 4 (PS4), no modo jogador principal, a história do jogo é contada a partir do ponto de vista da Lara Croft (personagem principal do jogo). O objeto de estudo foi elaborado a partir de três situações apresentadas em Tomb Raider: Definitive Edition, desenvolvido pela Crystal Dynamics e publicado pela Square Enix em 2014 (versão definitiva). As escolhas foram definidas pela disponibilidade de acesso tanto do Console quanto do jogo.

A coleta das situações para análise semiótica ocorreu no período de Março e Abril de 2018. Os pesquisadores interagiram com o jogo nesse período investigando situações relevantes que impactam em sua transformação entre o mundo real e a inserção no mundo virtual. Os dados coletados foram registrados através de funções disponíveis do próprio console (PS4) que permite registrar vídeo e fotos da tela durante a interação. A análise dos dados foi comparativa, utilizando três situações encontradas no jogo:

- A - Objeto definido como arma usado pela protagonista do jogo;

- B - Situação de impulsão da protagonista sobre um objeto;

- C - Situação desafiadora que a protagonista precisa resolver um enigma.

Os questionamentos da análise foram retirados da literatura consultada. Ao observar as três situações retiradas do jogo indagou-se:

- O que é isso? O que significa isso?

- A representação virtual do objeto/situação entrega as mesmas características do mundo real?

- As propriedades dos objetos representados em contexto de uso durante o jogo são mesmo realistas em comparação com o mundo real?

- A representação comportamental do objeto foi alterada do sentido real para o virtual?

\section{Análise e Discussão dos resultados}

\section{A - Um objeto definido como arma usado pela protagonista do jogo.}

O objeto em estudo é um machado de escalada, que a protagonista (Lara Croft) utiliza em determinadas situações do jogo, principalmente ao escalar paredes e atingir inimigos. Em termos de representação visual, o machado de escalada segue todas as características de forma/cor/volume/escala do mesmo objeto apresentado no mundo real, ou seja, a representação do objeto em si entre o real e o virtual são idênticos.

As propriedades do machado de escalada em contexto de uso no jogo são comprometidas perante a realidade, pois em determinadas ações da protagonista o machado de escalada é usado tanto em paredes no gelo quanto em paredes rochosas, ou seja, o metal na ponta estrema do machado não atinge profundidade de fixação ao encontrar um material com a mesma densidade de dureza (propriedades físico-químicas da matéria). Sendo assim, o comportamento do machado de escalada não é representado corretamente na situação de escalada em superfícies rochosas como no sentido real, onde o escalador, ao subir nessas paredes, utiliza ancoragem que são fixadas na rocha, outro elemento presente é o pó de magnésio para dar maior aderência e impedir a transpiração das mãos. A Figura 2 ilustra a investigação feita no objeto em estudo. 
Figura 2: Visão geral do objeto em estudo. (Fonte: A - Dj3r0m (2018) | B - LiveAbout (2018) | C - Outside Pursuits (2019)).
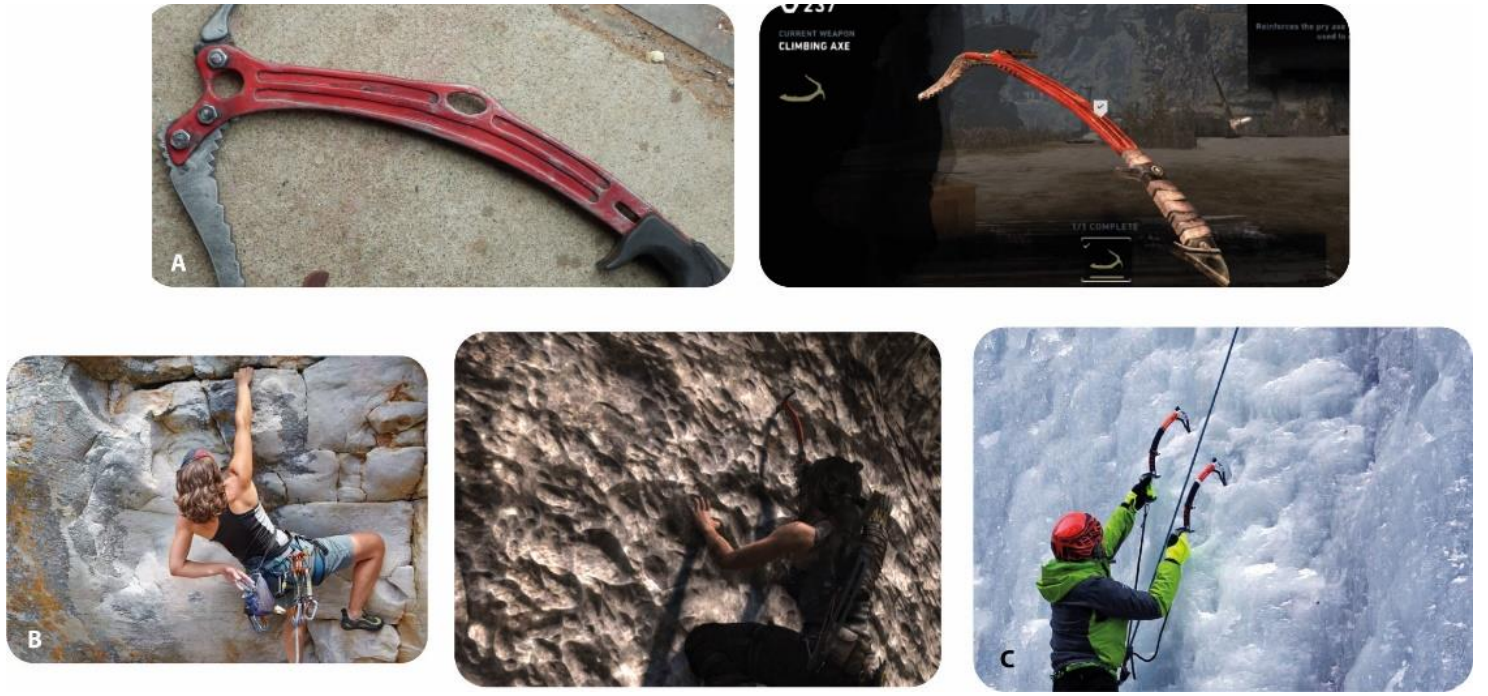

\section{B - Situação de impulsão da protagonista sobre um objeto.}

A situação em estudo é uma ação que deve ser realizada por Lara quanto se depara com algum obstáculo alto, na qual precisa de impulsão para subir e seguir no jogo. No caso em estudo, é uma parede de madeira tintada de branco. Ao perceber a tinta branca impregnada no material de madeira o jogador precisa entender que ali a protagonista exerce impulso para conseguir subir e ultrapassar obstáculos. A representação do material de madeira e tinta tem as mesmas características no mundo real. As propriedades em contexto de uso durante o jogo são realistas, o objeto madeira tintada pode ser representado da mesma forma no mundo real.

Da representação comportamental perdeu o sentido real quando a protagonista interage com o objeto, pois ao tentar subir a parede de madeira sinalizada com tinta branca, precisa ganhar impulso. Nessa situação, a protagonista utiliza as mãos, que supostamente estão fixadas na madeira lisa, e essa ação impulsiona para subir por completo a parede. Em um sentido real, a protagonista precisaria de algo que a sustentasse para subir por completo tal parede: o machado de escalada, ou uma fecha com corda - outro elemento que a protagonista experiência durante o jogo. A Figura 3 ilustra a investigação:

Figura 3: Visão geral do objeto em estudo. (Fonte: A - Freepik Company S.L. (2019)).
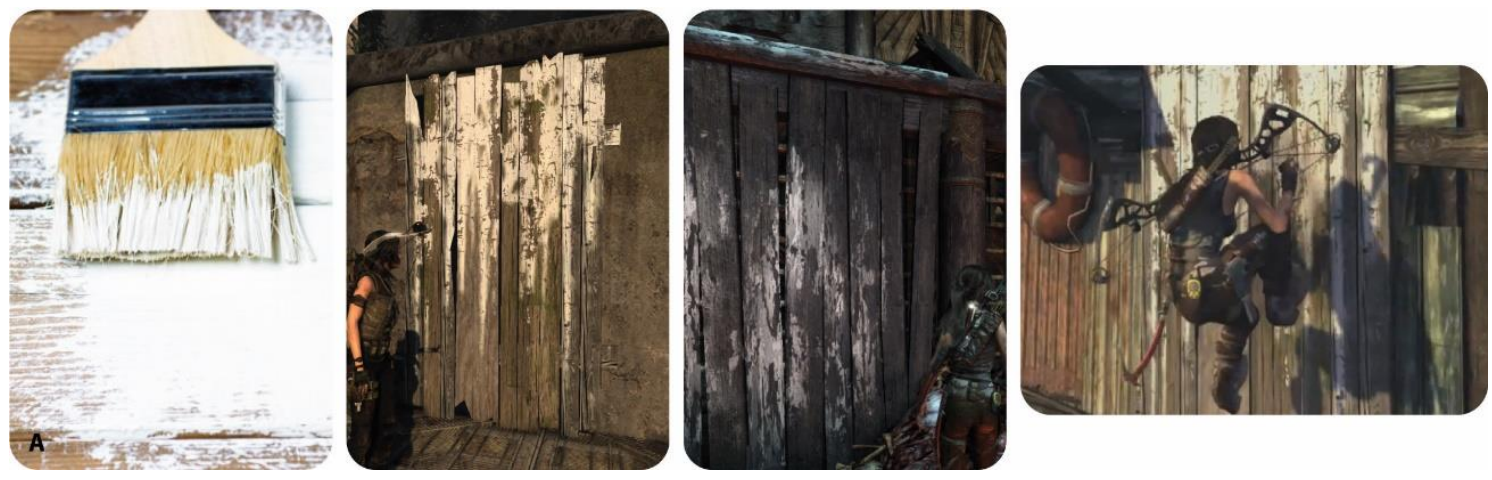

\section{C - Situação desafiadora que a protagonista precisa resolver um enigma do jogo.}

A situação em estudo é um desafio extra encontrado no jogo, denominado de tumba secreta câmara escondida que guarda enigma e item especial, considerado uma tarefa desafiadora para o jogador. A tumba analisada neste estudo está situada na Favela - chamada de câmara

Anais do 9o Congresso Internacional de Design da Informação | CIDI 2019

Proceedings of the 9th Information Design International Conference 
do julgamento. Existe uma diversidade de ações que competem a Lara Croft realizar para solucionar o enigma, no qual focamos no objeto galão amarelo.

A representação virtual do galão segue as caraterísticas do mundo real. Suas propriedades representadas no contexto de uso são compatíveis com a realidade, como suporte de peso para segurar ou impedir o movimento de algo; porém, o comportamento do objeto perante a situação no jogo foi alterado. O galão amarelo virtual é usado para sustentar o peso de uma plataforma metálica (compreendida como parte de um destroço de um avião). As propriedades físico-químicas da matéria do galão não teriam capacidade suficiente para segurar a plataforma a fim de que Lara siga no enigma. A solução, no contexto, é usar pelo menos três galões (espalhados pelo cenário), que com o peso pendem e sustentam a plataforma metálica. Assim, a protagonista usa a plataforma estagnada para se impulsionar e escalar a parede, que leva a um baú e soluciona a etapa da câmara de julgamento. A Figura 4 ilustra a investigação feita na situação em estudo:

Figura 4: Visão geral do objeto em estudo. (Fonte: A - Inspirationfeed (2018)).
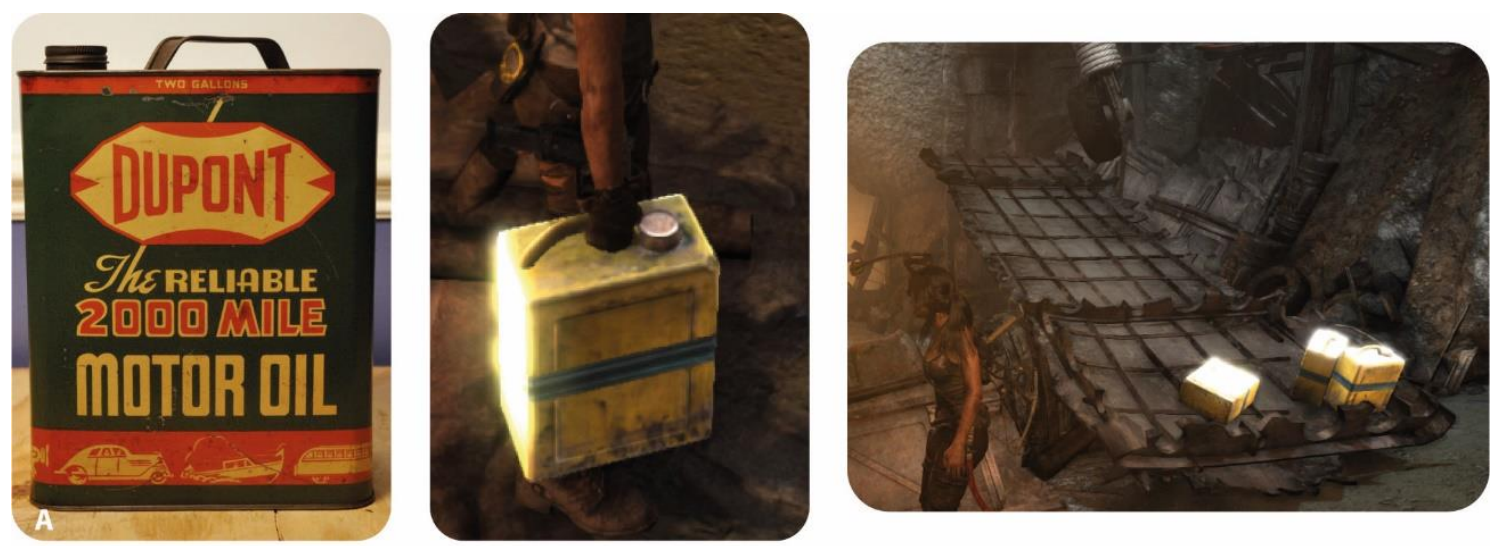

Portanto, as características de representação visual dos elementos analisados no jogo são muito próximas da realidade, o que pode facilitar o entendimento do que é e o que significa para o jogador. Das propriedades dos objetos em contexto de uso no jogo, o empasse nas propriedades físico-químicas da matéria, quando comparado no mundo real, são questionáveis, visto que o machado de escalada não consegue profundidade de fixação ao encontrar um material com a mesma densidade de dureza; e três galões não seriam suficientes para estagnar um destroço de avião.

A alteração relevante da representação real para o virtual foi o comportamento dos objetos. As três situações elencadas neste estudo receberam modificações ao serem utilizadas no ambiente virtual, isto é: a personagem utiliza o machado de escalada para subir paredes rochosas; algo/alguma coisa de madeira tintada em branco significa um efeito de impulsão; e galões são elementos de peso elevado.

Sendo assim, a representação comportamental dos objetos analisados no jogo transmitiu uma informação com um significado diferente do mundo real. A relação de estímulos cognitivos no jogador pode comprometer a interpretação correta destes objetos, com isso, afeta a jogabilidade e a capacidade de interpretação dos significados carregados nestes signos, por outro lado, o designer de jogos precisa sustentar, na projetação, alguns requisitos e restrições para permitir o fluxo da jogabilidade e a interação com o jogador.

No nível semiótico, os signos analisados neste estudo ganham valor simbólico, pois carregam em si aspectos de referencialidade existente no mundo real e a capacidade de interpretar e comunicar algo para o jogador. Do olhar semântico temos o entrave ocasionado pelo processo de concepção do jogo, que precisa nivelar a significação para preencher os mecanismos que fazem com que a narrativa do jogo aconteça.

Como foi comprovado nas situações investigadas no estudo, as propriedades do tipo de matéria foram alteradas, ou seja, as entidades semânticas, explicadas por Kessing, Tutenel e 
Bidarra (2012), estavam presentes, eram físicas (existem no mundo real), são percebidas e reconhecidas, porém receberam representação abstrata no mundo virtual perante comportamento do objeto, reforçando o que os mesmos autores relatam em seu estudo: jogos de exploração e a interatividade comprometem o aprofundamento semântico e dificultam o fornecimento de produto espacialmente imersivo, consistente e verossímil.

\section{Considerações finais}

A proposta de investigação entre o mundo real e a representação virtual em situações encontradas no jogo Tomb Raider trouxe uma discussão despretensiosa da qualidade representacional e como essa informação transmite o significado para o jogador.

Os achados corroboram com o estudo de Kessing, Tutenel e Bidarra (2012), ou seja, a qualidade da representação visual é verossímil ao realismo, mas existe a lacuna perante o que o jogador visualmente vê e o comportamento dos objetos durante a atuação no jogo.

Portanto, as propriedades e comportamento dos objetos representados em contexto de uso durante o jogo são diferentes em comparação com o mundo real, acredita-se que por questões de desenvolvimento do jogo essas mudanças são fundamentais, e sofrem alterações para manter o fluxo interativo.

Com isso, os achados deste estudo podem dizer que ao desenvolver um evento ou um desenho de nível os designers de jogos precisam modificar as propriedades e/ou comportamento de uso dos objetos do mundo real para o mundo virtual.

Enfim, por outro viés, quem fornece o significado aos signos são as próprias pessoas, tanto quem desenvolve quanto quem joga, reforçando a ideia de Salen e Zimmerman (2003) que somos criadores ativos de significados, ou então o jogador cria uma conversação, que de acordo com Lightbown (2015) faz com que o jogador aprenda a linguagem e converse com o jogo, e se houver similaridade entre outros jogos vivenciados fica mais fácil o entendimento.

Por isso, como desdobramento, precisa-se verificar com diferentes níveis de jogadores o quanto essas diferenciações/alterações entre o real e o virtual afetam sua interpretação e o processo de fluxo narrativo durante o jogo. Além disso, utilizar-se de outras vertentes teóricas, por exemplo, a retórica processual de Bogost (2007) podem resultar em novos achados.

\section{Referências}

Bogost, I. (2007). Persuasive games: the expressive power of videogames. The MIT Press.

DJ3ROM (2018). [TOMB RAIDER] Lara's climbing axe. Disponível em: $<$ https://www.deviantart.com/dj3rOm/art/TOMB-RAIDER-Lara-s-climbing-axe381549858>. Acesso em: 20 mai 2018.

Dondis, D. A. (2007). Sintaxe da linguagem visual. $3^{a}$. Ed. São Paulo: Martins Fontes.

Eco, U. (1979). A Theory of semiotics. Bompiani/Milan:Midland Book Edition.

Erwig, M., Smeltzer, K., \& Wang, X. (2017). What is a visual language? Journal of Visual Languages and Computing 38, p. 09-17.

Freepik Company S.L. (2019). Pincel em uma superfície de madeira pintada, fundo, cópia espaço. Disponível em: <https://br.freepik.com/fotos-premium/pincel-em-umasuperficie-de-madeira-pintada-fundo-copia-espaco_4611093.htm>. Acesso em: 23 jun 2019.

Frascara, J. (2004). Communication design: principles, methods, and practice. New York: Allworth Press.

Gil, A. C. (2017). Como elaborar projetos de pesquisa. 6. ed. - São Paulo: Atlas.

Hartley, J. (2004). Communication, Cultural and Media Studies: The Key Concepts. $3^{\mathrm{a} e d .}$

Anais do 9ำ Congresso Internacional de Design da Informação | CIDI 2019 
Routledge/Taylor \& Francis Group.

Horn, R. (1999). Information Design: Emergence of a New Profession. In: Information Design. Jacobson, Robert E (Org.). Massachusetts: MIT Press.

IIID - International Institute for Information Design. Definitions. Disponível em: <http://www.iiid.net/home/definitions>. Acesso em: 19 Abril de 2018.

Inspirationfeed (2018). 25 Inspiring Vintage Motor Oil Packaging Designs. Disponivel em: $<$ https://inspirationfeed.com/40-inspiring-vintage-motor-oil-packaging-designs>. Acesso em: 20 mai 2018.

Kessing, J., Tutenel, T., \& Bidarra, R. (2012). Designing Semantic Game Worlds. Conference: Proceedings of the The 3rd. workshop on Procedural Content Generation in Games, ACM, p. 02.

Lightbown, D. (2015). Designing the User Experience of Game Development Tools. Boca Raton: CRC Press Taylor \& Francis Group.

Liveabout (2018). Essential Rock Climbing Skills. Disponível em: <https://www.liveabout.com/rock-climbing-basics-4140423>. Acesso em: 20 mai 2018.

Malamed, C. (2011). Visual Language for Designers: Principles for Creating Graphics that People Understand. Rockport Publishers.

Newzoo (2017). Infográfico The Brazilian Gamer. Disponível em: <https://newzoo.com/insights/infographics/the-brazilian-gamer-2017>. Acesso em: 18 Abril de 2018.

Novak, J. (2012). Game Development Essentials: An Introduction. $3^{\mathrm{a} e d .}$ NY/Delmar: Cengage Learning,.

Outside Pursuits (2019). The 5 Best Ice Axes - [Reviews \& Guide 2019]. Disponível em:<https://www.outsidepursuits.com/best-ice-axe>. Acesso em: 23 jun 2019.

Peirce, C. S. (2005). Semiótica. São Paulo: Editora Perspectiva.

Pettersson, R. (2012). It Depends: ID - Principles and guidelines. Tullinge, Sweden, $4^{\text {a }}$ Ed.

Redish, J. C. (2000). What Is Information Design? Technical Communication, Volume 47, №. 2 , May, p. 163-166.

Salen, K. \& Zimmerman, E. (2004). Rules of Play: Game Design Fundamentals. The MIT Press.

Saussure, F. (1971). Cours de linguistique générale, ed. Bally, Charles e Sechehaye, Albert. Paris:Payot.

Tutenel, T. et al (2008). The Role of Semantics in Games and Simulations. ACM Computers in Entertainment, Vol. 6, $\mathrm{n}^{\circ} .4$.

\section{Sobre os autores}

André Schlemmer, Mestre, UFPR, Brasil, <schlemmer.andre@gmail.com>

Diego Normandi, Mestre, USP, Brasil, <diegonmd@usp.br> 